\author{
Preventive Care in Nursing and Midwifery Journal \\ $2020 ; 10(2): 26-33$
}

\title{
Study of Palliative Care Needs among Stroke Patients Referred to Physiotherapy Centers
}

\author{
Fathollahi $\mathrm{T}^{1} \mathbb{\mathbb { E }}$, Baljani $\mathrm{E}^{2^{*}}$, Rezaee moradali $\mathrm{M}^{3} \mathbb{E}$ \\ ${ }^{1}$ Department of nursing, urmia branch, Islamic Azad University, urmia, Iran \\ ${ }^{*}$ Department of nursing, urmia branch, Islamic Azad University, urmia, Iran \\ ${ }^{3}$ Department of midwifery, urmia branch, Islamic Azad University, urmia, Iran
}

*Corresponding Author: Islamic Azad University, urmia

Tel: 0098- 9141404082

Email: baljanies@gmail.com

Received: 27 July $2020 \quad$ Accepted: 11 Nov 2020

\begin{abstract}
Background: Patients with stroke need professional care and identifying the palliative needs of these people is the basis for care planning by health managers.

Objectives: The present study aimed to determine the palliative care needs of stroke patients and the factors that affect these needs.

Methods: The population of this cross-sectional descriptive study was the patients referred to physiotherapy centers in Mako city in 1398. A total of 160 patients were selected based on convenience sampling. The data collection tool was a two-part questionnaire. In the first part, demographic characteristics and in the second part, the questionnaire of palliative care needs in specific patients was completed. Descriptive tests, mean comparison, and Pearson correlation was used to analyze the data using SPSS software version 16.

Results: The need for palliative care can vary in different fields. For example, having problems in daily life in the field of daily life activities (2.03-0.24), pain in the field of physical symptoms (2.36.07.07), dependence on others for care in the field of control over living affairs $(1.7210 .82)$, tendency to talk about illness in the field of social problems, (2/71/71/71), fear of metastasis in the field of mental problems, $(2.972$ $0.22)$, understanding the meaning of death in the field of spiritual problems $(2.87 \pm 0.48)$, and loss of income due to diseases in the field of financial problems (2.63 89 0.89). Independent group t-test showed that the mean scores of palliative care needs of patients referred to physiotherapy centers in the two groups of men and women were not significantly different $(\mathrm{t}=92.1, \mathrm{p}=0.057)$. However, One-way analysis of variance showed that the average palliative care needs of patients referred to physiotherapy centers based on their level of education had a significant difference $(\mathrm{f}=486.4, \mathrm{p}=0.014)$.

Conclusion: The results of the study showed that nurses and health system managers with knowledge of the needs of palliative care for patients with stroke can put training programs on discharge and disease management at home on their agenda.
\end{abstract}

Keywords: stroke, palliative care needs, physiotherapy, stroke patient

\section{Introduction}

According to reports, every year forty million people in the world need palliative care. However, only $14 \%$ receive palliative care. About $78 \%$ of these needy people live in low- and middleincome countries. According to the World Health Organization, the diseases that require palliative care include cardiovascular disease $5.3 \%$, cancer $34 \%$, chronic lung disease $3.1 \%$, AIDS $7.5 \%$, and diabetes $6.4 \%$ [1].
However, reports indicate that many countries in the world do not have palliative care programs in the structure of their health system [2]. The barriers to providing palliative care in the world include lack of government support for palliative care services, lack of readiness of professionals to provide palliative care services, limited access to painkillers, limited resources, and lack of familiarity of policymakers with palliative care, 
negative community attitudes, and socio-cultural issues [3].

In stroke patients whose disease status is chronic and progressive, complete palliative care is required so they would benefit from the rest of their lives [4]. Palliative care needs went beyond self-care needs. After diagnosing the disease, these patients need various palliative care, so paying attention to their needs has been emphasized by specialists in the presence of the treatment team [5].

People prefer to receive care services in their homes with their families [6]. The results of previous studies also indicate that home-based palliative therapies have beneficial effects on the physical, mental, psychological, social, and economic aspects of patients. They can reduce the costs of the health system, shorten the duration of hospitalization, and prevent readmission of patients. [7]. Also, with the implementation of palliative care, the continuation of post-discharge care is facilitated, and the patient can easily benefit from the facilities of different centers [8].

According to a review of literature, despite some limitations in Iran, the self-care needs of chronic patients have been studied for which some solutions have been proposed [5]. Palliative care seeks to improve the quality of life of patients and their families by identifying, preventing, and relieving physical, mental, and emotional pain. Palliative care programs require identifying the needs of palliative care in chronic patients, especially stroke $[9,10]$.

However, in Iran, we have limited information about the attention required for palliative care among nurses and stroke patients who have received palliative care. Therefore, the present study aimed to determine the needs of palliative care and its influential factors on stroke patients.

\section{Methods}

The population in this cross-sectional descriptive study included all stroke patients who had referred to physiotherapy centers in Mako city for six months from June to November 2017. According to the study of Fattahi et al. (2008) and the ratio, the number of samples was calculated as 160 [11]. We used convenience sampling, so each of the stroke patients referred to physiotherapy centers who met the study conditions entered the study. The code of study ethics was obtained through the ethics committee of the Mahabad branch of Azad University. (IR.IAU.MAHABAD.REC.1398.001). A questionnaire was used to collect data. The questionnaire has two parts, the first part was the demographic characteristics, and the second part was the problems and needs in palliative care questionnaire. This questionnaire has not been used in domestic studies before. Dimensions of this questionnaire include daily life activities (6 items), physical symptoms (16 items), ability to do life (item 6), social problems (item 10), psychological problems (10 items), spiritual problems ( 8 items), financial problems (4 items), need knowledge and information (2 items). To score this questionnaire, a Likert rating was used as yes (score 3), somewhat (score 2), and no (score 1) [12]. The validity of the questionnaire in osse studies (2007) was calculated by Cronbach's alpha method of 0.80 . The validity of the questionnaire was obtained through face validity and content validity. After translation and reverse translation, the questionnaire was given to 10 faculty members of the Faculty of Nursing of Urmia University of Medical Sciences and Urmia Azad University, and their corrective opinions were applied. To obtain reliability, the questionnaire was given to 20 patients referred to physiotherapy centers who were excluded from the study, and the reliability of the questionnaire was calculated to be 0.78 with Cronbach's alpha. Inclusion criteria were the stroke patients who have been medically diagnosed by a neurologist, obtaining informed consent to participate in the study, having a referral from a physician for physiotherapy, age over 18 years, and the ability to speak. The exclusion criteria were unwillingness to continue cooperation in research and loss of ability to speak and the possibility of participating in filling out a questionnaire, having a history of mental or emotional problems, and brain tumors. SPSS software version 24 was used to enter and analyze the data. Descriptive tests were used to determine the mean, standard deviation. And the independent group's t-test and one-way analysis of variance was used to compare the means due to the normality of the variable distribution of palliative care needs. Pearson test was used to determine the correlation. The significance level was considered less than 0.05 . 


\section{Results}

Table 1 shows the demographic characteristics of the participants. The results showed that the highest need for palliative care in the field of daily life activities of patients referred to Mako Physiotherapy Centers had some problems in daily life activities, such as bathing, dressing, and going to the toilet (mean 2.03 and standard deviation 0.24). Also, most of the palliative care needs of stroke patients in the field of physical symptoms were related to pain (mean 2.36 and standard deviation of 0.07). In the area of authority in life affairs, the highest need for palliative care was related to dependence on others for care (mean 1.72 and standard deviation 0.82). Also, most of the palliative care needs of stroke patients in the field of social problems were associated with "willingness to talk about the disease" (mean 2.7 and standard deviation 0.71). Most of the palliative care needs of patients in this study in the field of mental problems were related to fear of metastasis (mean 2.97 and standard deviation 0.22 ). Also, the results showed that the most palliative care needs of patients in the field of spiritual problems, financial problems, and the need for knowledge and information were respectively associated with understanding the meaning of death (mean 2.87 and standard deviation of 0.48 ), loss of income due to illness (mean 2.63 and standard deviation of 0.89) and an average of 1.23 and a standard deviation of 0.64 . In this study, the findings showed that the most needs for palliative care were related to the psychological dimension (2.15. 0.32) and social dimension (2.09 54 0.54) (Table 2).

Table 1: Demographic characteristics of stroke patients participating in the study

\begin{tabular}{cccc}
\hline \multirow{2}{*}{ Gender } & & Number & Percentage \\
\cline { 2 - 4 } & male & 82 & 51.3 \\
\cline { 2 - 4 } Education & female & 78 & 48.8 \\
\cline { 2 - 4 } & illiterate & 140 & 85.5 \\
\cline { 2 - 4 } age & Non-high school graduate & 18 & 11.3 \\
\cline { 2 - 4 } Marital Status & Diploma & 2 & 1.3 \\
\cline { 2 - 4 } & Mean (Standard deviation) & $(12.49) 70.01$ & \\
\cline { 2 - 4 } Occupational & Married & 124 & 77.5 \\
\cline { 2 - 4 } status & Single & 28 & 17.5 \\
\cline { 2 - 4 } & Widow & 20 & 5 \\
\cline { 2 - 4 } Other diseases & Employee & 76 & 47.5 \\
\cline { 2 - 4 } & housewife & 64 & 40 \\
\cline { 2 - 4 } & Other occupations & 136 & 15 \\
\hline
\end{tabular}

Table 2: Dimensions of palliative care needs of patients referred to Sina Physiotherapy Center in Mako city 1398

\begin{tabular}{ccc}
\hline Dimensions of palliative care needs & Mean & Standard deviation \\
\hline Daily life activities & 1.01 & 0.08 \\
\hline Physical symptoms & 1.37 & 0.32 \\
\hline The power to do life & 1.24 & 0.48 \\
\hline social problems & 2.09 & 0.54 \\
\hline mental health problems & 2.15 & 0.32 \\
\hline Spiritual problems & 1.93 & 0.32 \\
\hline Financial Problems & 1.75 & 0.45 \\
\hline Need knowledge and information & 1.23 & 0.64 \\
\hline
\end{tabular}

Also, the results of one-way analysis of variance showed that the palliative care needs of stroke patients participating in this study had a statistically significant difference regarding the education levels $(\mathrm{f}=4.43, \mathrm{p}=0.01)$. However, the independent group t-test showed that the palliative 
care needs of stroke patients did not differ significantly between the male and female groups $(t=92.1, p=0.057)$. Also, the results of the Pearson correlation test showed that the scores of palliative care needs were not significantly related to the age of patients referred to physiotherapy centers in Mako city $(r=-0.13, p=0.25)$. Also, the results of one-way analysis of variance showed that the mean scores of palliative care needs of stroke patients participating in this study concerning job $(\mathrm{p}=0.054, \mathrm{f}=0.037)$ and marital status $(\mathrm{p}=0.43, \mathrm{p} / 848) .0=\mathrm{f})$ did not have a significant difference (Table 3 ).

Table 3: Comparison of palliative care needs of patients referred to physiotherapy centers in Mako city based on education level

\begin{tabular}{|c|c|c|c|c|c|c|}
\hline & $\begin{array}{l}\text { General Palliative } \\
\text { Care Needs }\end{array}$ & Mean & $\begin{array}{l}\text { Standard } \\
\text { deviation }\end{array}$ & df & statistics & sig \\
\hline \multirow{3}{*}{ education } & illiterate & 110.70 & 12.14 & \multirow{3}{*}{2} & \multirow{3}{*}{$\mathrm{f}=4.43$} & \multirow{3}{*}{0.01} \\
\hline & $\begin{array}{l}\text { Non high school } \\
\text { graduate }\end{array}$ & 123 & 10.97 & & & \\
\hline & Diploma & 118 & 18.03 & & & \\
\hline \multirow{2}{*}{ Gender } & Man & 12.56 & 1.15 & \multirow{2}{*}{78} & \multirow{2}{*}{$\mathrm{t}=1.92$} & \multirow{2}{*}{0.057} \\
\hline & Female & 13.25 & 1.09 & & & \\
\hline \multirow{3}{*}{ Job } & Free & 11.15 & 1.15 & \multirow{3}{*}{2} & \multirow{3}{*}{$f=0.037$} & \multirow{3}{*}{0.054} \\
\hline & Employee & 17.32 & 1.16 & & & \\
\hline & housewife & 12.79 & 1.09 & & & \\
\hline \multirow{3}{*}{$\begin{array}{l}\text { Marital } \\
\text { status }\end{array}$} & Married & 13.41 & 1.13 & \multirow{3}{*}{2} & \multirow{3}{*}{$\mathrm{f}=0.848$} & \multirow{3}{*}{0.432} \\
\hline & Widow & 5.25 & 1.10 & & & \\
\hline & Single & 13.16 & 1.08 & & & \\
\hline \multicolumn{2}{|l|}{ Age } & 70.10 & 12.49 & \multirow{2}{*}{\multicolumn{2}{|c|}{$\mathrm{r}=-0.13$}} & \multirow{2}{*}{0.25} \\
\hline \multicolumn{2}{|c|}{ Points for palliative care needs } & 13.12 & 1.12 & & & \\
\hline
\end{tabular}

\section{Discussion}

The results of this study showed that the highest need for palliative care for stroke patients in the field of daily living activities was related to daily living activities such as bathing, dressing, and going to the toilet, while activities such as cycling and driving and housework were in low priority in the palliative care needs. Regarding the interpretation of this result from the present study, it seems that patients consider the independence of action in social and basic health activities to be very important and consider any restriction in such daily activities of life as a disorder of independence. It should be noted that the presence of social and cultural standards to compensate for the daily activities of life due to chronic diseases has been introduced in assessing the care needs of patients [13]. In other words, assistance from family members and social institutions to compensate for the dependence on Illness is important in assessing patients' need for care. On the other hand, the results of this study are comparable to the study of Haghgoo et al. (2013). According to Haghgoo et al., since disruption in basic daily life activities such as going to the toilet and bathing harms other areas of life such as meeting psychosocial needs, so in the eyes of patients, disruption in these daily life activities has been introduced as a basic need [14].

The results of this study also showed that most of the palliative care needs of patients with stroke in the field of physical symptoms were related to pain. Consistent with our findings, Christopher et al. (2010) showed that $50 \%$ of stroke patients reported pain-related palliative care needs [15]. Pain is very important for patients because it is a significant problem for humanity and can be followed by sleep disorders, depression, and other health problems [14]. Boatmen et al. reported that $36.5 \%$ of stroke patients had pain. They posited that pain after stroke was a common complication, which could harm patients' quality of life. Therefore, physicians and health care providers should consider patients' need for pain care at each patient visit [16].

The results of this study showed that most of the palliative care needs of stroke patients in the area of "authority for life affairs" were related to being 
dependent on others for care. This shows the importance of independence in patients' lives. The results of ullberg et al. (2015) are consistent with our results [17]. The most important complication of stroke patients is a decrease in the sensory and motor capacity of the limbs. Since the reduced mobility and low levels of activity cause the loss of independence in life activities, social isolation, fatigue, and disability, patients need to have the necessary authority in life [18]. Nikanfar et al. (2017) posit that independence in the activities of daily living causes and improves the quality of life and promotes the presence of the individual in social, occupational, and recreational activities [19].

The results of the present study also showed that most of the palliative care needs of stroke patients in the field of social problems were related to "willingness to talk about the disease". With the onset of symptoms of the disease, many questions arise in the mind of the person, and many things may be questionable for the patient and his family members. Patients would like to know enough about the symptoms of the disease to the stages of diagnosis and available treatments, its complications, and even the costs imposed on the patient and his family. Sharma et al. stated that clear communication and information was a prerequisite for understanding patient satisfaction with nursing care [20]. Patients emphasize the importance of receiving appropriate information, so it is necessary to complete information to increase their satisfaction. The nurses' explanation must be clear so that they have a good understanding of what the nurses are saying [21].

The results of this study showed that most of the palliative care needs of stroke patients in the field of mental problems were related to fear of metastasis because they do not have accurate information about metastasis. This fact is confirmed in the demographic information from the results. It should be noted that the majority of patients participating in this study are illiterate and do not have accurate medical information. They think they are more prone to metastasis due to stroke than other people in the community. This may indicate that there is insufficient training of health care providers for their patients. Berry et al. (2008) also showed that the training of the caregiver team is not enough, with which patients are dissatisfied [22].

The results of this study also showed that most of the palliative care needs of stroke patients in the field of spiritual problems were related to understanding the meaning of death. The researcher's experience over several years in different parts of the hospital, such as neurology shows that when the treatment of a disease takes a chronic course, in the long run, it has negative effects on various aspects of health. Spiritual health is one of the aspects of health. Therefore, the long course of stroke and its disabilities can have negative effects on various aspects of spiritual health. It should be noted that understanding the meaning of death in incurable patients is associated with several factors, such as social support and patients' level of awareness in different cultures [23]. Some consider understanding the meaning of death as a kind of mental preoccupation with death,

which may lead to some negative consequences and cause anxiety and depression [24].

The results of this study showed that most of the palliative care needs of stroke patients in the area of financial problems were related to loss of income due to illness. According to this result, it seems that most patients had many problems in earning income and meeting the financial needs for their treatment and life needs. Families face several problems due to not having enough income for medical and rehabilitation services and living expenses after suffering a stroke. Jafari et al. also pinpointed economic problems after the disease. [23]. McKevitt (2011) reported that 18\% of patients have financial problems after suffering a stroke [25].

The present study found that the mean scores of palliative care needs of stroke patients did not differ significantly between men and women referred to physiotherapy centers. However, Villar et al. (2002), in their cross-sectional study, showed that women were more in need of palliative care than men [25]. On the other hand, Jafari et al. (2011) stated that women benefit more from social support and spiritual counseling than men to adapt to the needs of palliative care [23].

Also, the average palliative care needs of stroke patients referred to physiotherapy centers have a significant difference based on their level of education. 
People who were not very educated expressed less need for palliative care than other educational groups, which is consistent with the results of studies conducted in other countries [26]. Regarding the interpretation of this result, the higher the level of literacy of patients, the more information resources they will benefit from, and the higher will be their expectations.

In this study, palliative care needs were not significantly related to the age of stroke patients. In the study of MS Kuwait, no significant difference was observed between the age group of patients and the care needs of stroke patients [25]. In another study, however, there was an inverse relationship between the age and care needs of stroke patients [24].In general, the results of studies on the relationship between age and palliative care needs of stroke patients have not been similar. For example, Qaygaran et al. (2011) indicates that pain was significantly more common in stroke patients aged 1 to 4 years, and also in patients under four years of age, patients' needs were the lowest [27]. Fattahi et al. (2008) showed that the quality of life of stroke patients was age-dependent, so the quality of life was lower in young people than in older people [28]. In this study, there was no significant difference in the mean scores of palliative care needs of stroke patients referred to Sina Physiotherapy Center based on their occupational status. The needs of stroke patients depend on several factors that have a complex effect on each other. In other words, the level of education and the level of awareness of the condition and treatment process, and the level of employment and social relationships can be effective and are related to the level of patients' needs. [25]. Employed people have more social interactions than the unemployed or housewives, and their relationships can improve their ability to cope with disabilities caused by stroke [26]. The high rate of employment of patients in government centers and offices is related to those who have a higher level of literacy, and as mentioned earlier, patients with higher levels of literacy had fewer needs than illiterate patients.

In this study, there was no difference in the mean palliative care needs of stroke patients referred to Sina Physiotherapy Center based on their marital status. However, various studies have emphasized the positive effect of social support from spouses and family members [29]. Married people seem to have more social support than single people. Spouses and children can meet the needs of patients.

\section{Conclusion}

Stroke patients face many disabilities and create many problems for families and a country's health system [4]. The results of this study revealed the palliative care needs of patients with stroke and showed the importance of these needs and their various aspects. Nurses and health system managers, while being aware of the palliative care needs of this group of patients, can put training programs on discharge and disease management at home on the agenda using the findings of this study.

\section{Acknowledgements}

The authors of the article would like to express their gratitude to the stroke patients who referred to the physiotherapy centers and the esteemed officials of the mentioned centers. This article is the result of a Master's thesis approved by the Islamic Azad University, Urmia Branch, and thus the authors are indebted to the Vice-Chancellor for Research.

\section{Conflict of interest}

Authors declare no conflict of interest in this study.

\section{References}

1. Rassouli M, Sajjadi M. Palliative care in Iran: Moving toward the development of palliative care for cancer. Am J Hosp Palliat Care. 2016; 33(3): 240-44.

2. Creutzfeldt CJ, Holloway RG, Walker M. Symptomatic and palliative care for stroke survivors. J Gen intern med. 2012; 27(7): 853-60.

3. Cowey E. End of life care for patients following acute stroke. Nurs Stand. 2012; 26(27): 42.

4. Ntlholang O, Walsh S, Bradley D, Harbison J. Identifying palliative care issues in inpatients dying following stroke. Ir J Med Sci. 2016; 185(3): 741-44.

5. Dalvandi A, Heikkilä K, Maddah S, Khankeh H, Ekman S-L. Life experiences after stroke among Iranian stroke survivors. Int Nurs Rev. 2010;57(2):247-53. 
6. Harding R, Epiphaniou E, Hamilton D, et al. What are the perceived needs and challenges of informal caregivers in home cancer palliative care? Qualitative data to construct a feasible psycho-educational intervention. Support Care Cancer. 2012;20(9):1975-82.

7. Koopmans RT, Lavrijsen JC, Hoek JF, Went PB, Schols JM. Dutch elderly care physician: a new generation of nursing home physician specialists. J Am Geriatr Soc. 2010; 58(9):180779.

8. Young AJ, Rogers A, Addington-Hall JM. The quality and adequacy of care received at home in the last 3 months of life by people who died following a stroke: a retrospective survey of surviving family and friends using the Views of Informal Carers Evaluation of Services questionnaire. Health Soc Care Community. 2008; 16(4): 419-28.

9. Holloway RG, Arnold RM, Creutzfeldt CJ, et al. Palliative and end-of-life care in stroke: a statement for healthcare professionals from the American Heart Association/American Stroke Association. Stroke. 2014; 45(6): 1887-916.

10. Mazzocato C, Michel-Nemitz J, Anwar D, Michel P. The last days of dying stroke patients referred to a palliative care consult team in an acute hospital. Eur J Neurol. 2010; 17(1): 73-77.

11. Fattahi a, Azad a, Montazeri a. Quality of life among stroke patients in Kermanshah city. Journal of modern rehabilitation. 2008; 2(1): 1-8.

12. Osse BH, Vernooij-Dassen MJ ,Schadé E, Grol RP. A practical instrument to explore patients' needs in palliative care: the Problems and Needs in Palliative Care questionnaire short version. Palliat Med. 2007; 21(5): 391-99.

13. Bakken LN, Kim HS, Finset A, Lerdal A. Stroke patients' functions in personal activities of daily living in relation to sleep and socio-demographic and clinical variables in the acute phase after first-time stroke and at six months of follow-up. J Clin Nurs. 2012; 21(1314): 1886-95.

14. Haghgoo HA, Pazuki ES, Hosseini AS, Rassafiani M. Depression, activities of daily living and quality of life in patients with stroke. J Neurol Sci. 2013; 328(1-2): 87-91.

15. Burton CR, Payne S, Addington-Hall J, Jones A. The palliative care needs of acute stroke patients: a prospective study of hospital admissions. Age Ageing. 2010; 39(5): 554-59.
16. Ghayeghran A, Bakhshayesh Eghbali B, Azari P. Survey of Various Post Stroke Pain Syndromes and the Related Risk Factors. J Guilan Univ Med Sci. 2012; 21(82): 1-7.

17. Ullberg T, Zia E, Petersson J, Norrving B. Changes in functional outcome over the first year after stroke: an observational study from the Swedish stroke register. Stroke. 2015; 46(2): 38994.

18. Van Mierlo ML, Van Heugten CM, Post MW, Hajós TR, Kappelle LJ, Visser-Meily JM. Quality of life during the first two years post stroke: the Restore4Stroke cohort study. Cerebrovas Dis. 2016; 41(1-2): 19-26.

19. Nikanfar S, Kalantari M, Shafiee Z, Akbarzadeh-baghban A. The relationship between sensorimotor function of hemiplegic lower limb and independency in daily living activities in hemiplegic patients. Sci J Kurdistan Univ Med Sci. 2017; 22(2): 64-70. [In Persian]

20. Sharma R ,Sharma M, Sharma R. The patient satisfaction study in a multispecialty tertiary level hospital, PGIMER, Chandigarh, India. Leadership Health Serv. 2011; 24(1): 64-73.

21. Alimohammadi N, Taleghani F, Yousefi $\mathrm{H}$. Stroke Patients' Experiences Of Care :A Phenomenological Study. Nurs Midwifery J. 2015; 13(9): 799-807. [In Persian]

22. Berry D, Bradlow A, Courtenay M. Patients' attitudes towards, and information needs in relation to, nurse prescribing in rheumatology. $\mathrm{J}$ clin nurs. 2008;17(2):266-73.

23. Jafari M, Makarem A, Dalvandi A, Azimian M, Hosseini M. Determination of facilitators and barriers in post stroke life, in Kerman city. Modern Rehabilitation. 2011; 5(2): 54-62. [In Persian]

24. Naess H, Lunde L, Brogger J, WajeAndreassen U. Post-stroke pain on long-term follow-up: the Bergen stroke study. J Neurol. 2010; 257(9): 1446-52.

25. McKevitt C, Fudge N, Redfern J, et al. Selfreported long-term needs after stroke .Stroke. 2011; 42(5): 1398-403.

26. Moeller D, Carpenter C. Factors affecting quality of life for people who have experienced a stroke. Int J Ther Rehabil. 2013; 20(4): 207-16.

27. Ghayeghran Ar, Bakhshayesh Eghbali B, Hosseini Nejad M, Azari P, Kazem Nejad E. Survey Of Various Post Stroke Pain Syndromes 
And The Related Risk Factors. J Guilan Univ Med Sci. 2012; 21(82:1-7. [In Persian]

28. Fattahi a, Azad a, Montazeri a. Quality Of Life Among Stroke Patients In Kermanshah City. Modern Rehabilitation. 2008; 2(1): 1-8. [In Persian]
29. Ch'Ng AM, French D, Mclean N. Coping with the challenges of recovery from stroke: long term perspectives of stroke support group members. J Health Psychol. 2008; 13(8): 1136-46. 